\title{
Article
}

\section{Combinatorial Discovery of Lanthanum-Tantalum Oxynitride Solar Light Absorbers with Dilute Nitrogen for Solar Fuels Applications}

Santosh K Suram, Sean Fackler, Lan Zhou, Alpha T. N'Diaye, Walter S. Drisdell, Junko Yano, and John M. Gregoire

ACS Comb. Sci., Just Accepted Manuscript • DOI: 10.1021/acscombsci.7b00143 • Publication Date (Web): 27 Nov 2017

Downloaded from http://pubs.acs.org on December 1, 2017

\section{Just Accepted}

"Just Accepted" manuscripts have been peer-reviewed and accepted for publication. They are posted online prior to technical editing, formatting for publication and author proofing. The American Chemical Society provides "Just Accepted" as a free service to the research community to expedite the dissemination of scientific material as soon as possible after acceptance. "Just Accepted" manuscripts appear in full in PDF format accompanied by an HTML abstract. "Just Accepted" manuscripts have been fully peer reviewed, but should not be considered the official version of record. They are accessible to all readers and citable by the Digital Object Identifier (DOI®). "Just Accepted" is an optional service offered to authors. Therefore, the "Just Accepted" Web site may not include all articles that will be published in the journal. After a manuscript is technically edited and formatted, it will be removed from the "Just Accepted" Web site and published as an ASAP article. Note that technical editing may introduce minor changes to the manuscript text and/or graphics which could affect content, and all legal disclaimers and ethical guidelines that apply to the journal pertain. ACS cannot be held responsible for errors or consequences arising from the use of information contained in these "Just Accepted" manuscripts. 


\title{
Combinatorial Discovery of Lanthanum-Tantalum Oxynitride Solar Light Absorbers with Dilute Nitrogen for Solar Fuels Applications
}

\author{
Santosh K. Suram ${ }^{\mathrm{a}}$, Sean W. Fackler ${ }^{\mathrm{b}}$, Lan Zhou ${ }^{\mathrm{a}}$, Alpha T. N'Diaye ${ }^{\mathrm{c}}$, Walter S. \\ Drisdell $^{\mathrm{b}}$, Junko Yano ${ }^{\mathrm{b}, \mathrm{d} *}$, John M. Gregoire ${ }^{\mathrm{a}, *}$ \\ a Joint Center for Artificial Photosynthesis, California Institute of Technology, Pasadena, CA \\ 91125 \\ b Joint Center for Artificial Photosynthesis, Lawrence Berkeley National Laboratory, Berkeley, \\ CA 94720 \\ ${ }^{\mathrm{c}}$ Advanced Light Source, Lawrence Berkeley National Laboratory, Berkeley, CA 94720 \\ ${ }^{\mathrm{d}}$ Molecular Biophysics and Integrated Bioimaging Division, Lawrence Berkeley National \\ Laboratory, Berkeley, CA 94720 \\ *Email:jyano@lbl.gov \\ *Email: gregoire@caltech.edu
}

\begin{abstract}
Oxynitrides with the photoelectrochemical stability of oxides and desirable band energetics of nitrides comprise a promising class of materials for solar photochemistry. Challenges in synthesizing a wide variety of oxynitride materials has limited exploration of this class of functional materials, which we address using a reactive co-sputtering combined with rapid thermal processing method to synthesize multi-cation-multi-anion libraries. We demonstrate the synthesis of a $\mathrm{La}_{\mathrm{x}} \mathrm{Ta}_{1-\mathrm{x}} \mathrm{O}_{\mathrm{y}} \mathrm{N}_{\mathrm{z}}$ thin film composition spread library and its characterization by both traditional thin film materials characterization and custom combinatorial optical spectroscopy and X-ray Absorption Near Edge Spectroscopy (XANES) techniques, ultimately establishing structure-chemistry-property relationships. We observe that over a substantial La-Ta composition range the thin films crystallize in the same perovskite $\mathrm{LaTaON}_{2}$ structure with significant variation of anion chemistry. The relative invariance in optical band gap demonstrates a remarkable decoupling of composition and band energetics so that the composition can be optimized while retaining the desirable $2 \mathrm{eV}$ band gap energy. We also demonstrate the intercalation of diatomic nitrogen into the $\mathrm{La}_{3} \mathrm{TaO}_{7}$ structure, which gives rise to a direct-allowed optical transition at $2.2 \mathrm{eV}$, less than half the value of the oxide's band gap. These findings motivate further exploration of the visible light response of this material that is predicted to be stable over a wide range of electrochemical potential.
\end{abstract}

\section{Introduction}

Discovery of efficient photoanodes for generation of chemical fuels from sunlight has remained a significant challenge due to the need to simultaneously optimize band gap energy, band edge positions, and aqueous stability. Oxynitrides are an important class of materials for photoanode applications due to their potential for simultaneously exhibiting the (photo)electrochemical stability of oxides and the favorable band energetics of nitrides. Despite these advantages, investigations of oxynitrides have been primarily limited to either a single cation $^{1}$ or $\mathrm{AB}(\mathrm{O}, \mathrm{N})_{3}{ }^{2}$ based phases; the latter being a family of perovskites amenable to electronic structure calculations ${ }^{3}$ and development of different synthesis methods. ${ }^{4}$ Oxynitride 
phases are typically synthesized via ammonolysis which involves nitridation of oxide precursors by heating them in a flow of ammonia $\left(\mathrm{NH}_{3}\right)$ under careful control of processing conditions such as time, temperature, and pressure to kinetically enable formation of oxynitride phases under thermodynamic conditions that typically favor the competing nitride phases. ${ }^{1 \mathrm{~b}}$ These stringent constraints on reaction kinetics can preclude synthesis of an oxynitride phase by ammonolysis over practical lab time scales. Therefore, establishing a robust synthesis method for a given oxynitride phase using ammonolysis is often challenging. The debate on synthesizability of $\beta$ TaON phase ${ }^{5}$ from ammonolysis of $\mathrm{Ta}_{2} \mathrm{O}_{5}$ provides an illustrative example that exploration for new oxynitride phases using such kinetically controlled processes is a daunting task.

Several other oxynitride synthesis approaches ${ }^{6}$ such as chemical vapor deposition, ${ }^{7}$ intercalation, ${ }^{8}$ reactive cathodic arc evaporation, ${ }^{9}$ and wet-chemical processes ${ }^{2 b}$ also suffer from sensitivity to process parameters. Synthesis methods such as flux-asssisted nitridation and ammonothermal processes have provided control over morphology and point defects in the resulting oxyntride through delicate tuning of synthesis conditions, ${ }^{2 b}$ which limits their applicability for rapid exploration of new oxynitride phases for photoanode applications. Recently, Takata et al. ${ }^{10}$ reported tunability of photoelectrochemical performance in $\mathrm{LaMg}_{\alpha} \mathrm{Ta}_{1-}$ ${ }_{\alpha} \mathrm{O}_{1+3 \alpha} \mathrm{N}_{2-3 \alpha}$ solid solutions as a function of $\alpha$ by investigating the performance of a series of oxynitrides synthesized by thermal ammonolysis of the corresponding amorphous mixed oxide powders prepared via solution routes. This work highlights the importance of exploring both cation and anion compositions to optimize performance for optical and photoelectrochemical applications, with materials exploration currently limited by both the time-consuming serial synthesis method and the need to cast thin film electrodes in order to perform photoelectrochemistry experiments. ${ }^{11}$ Thus, there is a need for complementary technique(s) that enable rapid synthesis of multi-cation oxynitride materials, and multi-cation-muti-anion films in general, in thin film form.

Combinatorial and high throughput techniques have enabled the discovery of several photoabsorbers, electrocatalysts, and photoelectrocatalysts. ${ }^{12}$ Particularly, we have demonstrated discovery of several multi-cation oxide photoanode materials for application in solar fuels generators using combinatorial thin film libraries. ${ }^{13}$ These combinatorial investigations have focused on multi-cation-single-anion materials, and while physical vapor deposition (PVD) methods for exploring multi-anion compositions with a single cation have been developed, ${ }^{14}$ methods for exploring multi-cation-multi-anion materials space are relatively undeveloped. We previously described synthesis of $\beta$-TaON thin films by combining reactive sputtering and rapid thermal processing (RTP). ${ }^{15}$ This process uses an $\mathrm{O}_{2}, \mathrm{~N}_{2}$ mixture as a reactive gas and the anion composition is tuned by precisely controlling the partial pressures of $\mathrm{O}_{2}$ and $\mathrm{N}_{2}$. Since the reactively sputtered films do not generally produce crystalline oxynitride phases, ${ }^{16}$ crystallization is initiated by performing RTP to enable the necessary atomic scale diffusion while limiting bulk anion diffusion. Without this limit on bulk anion diffusion, the thin film would equilibrate with the annealing gas, altering the anion composition attained during the film deposition. Delinking the composition determination (controlled via reactive sputtering) and crystallization (controlled via RTP) enables exploration of composition-dependent oxynitride phase behavior without the need to optimize synthesis conditions for each phase. Reactive sputtering also provides more uniform anion composition through the thickness of the thin film compared to diffusion limited processes such as ammonolysis, which can be critical in determining the optical and photoelectrochemical proprties of oxynitrides. ${ }^{2 b}$ 
In the present work, we extend the PVD-RTP approach to synthesize multi-cation-multianion libraries by employing co-sputtering from multiple cation sources in the presence of a reactive gas plasma containing the desired anion species. In particular, we investigate the chemistry and phase behavior of a thin film composition spread library in the La-Ta-O-N system. This investigation is motivated by i) the presence of a $\mathrm{LaTaON}_{2}$ phase with a $2.0 \mathrm{eV}$ band gap ${ }^{17}$ nearly optimal for a photoanode in a tandem photoelectrochemical water splitting device ${ }^{18}$ and for the top absorber in a triple-junction light absorber for $\mathrm{CO}_{2}$ reduction ${ }^{19}$, and ii) the reported photocatalytic activity of $\mathrm{La}_{3} \mathrm{TaO}_{7}$ for water splitting reactions. ${ }^{20}$

To explore new oxynitride materials, combinatorial oxyntride synthesis must be combined with materials characterization methods that can map the structural and chemical properties of the thin film composition library. In the present work we employ combinatorial implementations of standard thin film composition and crystal structure characterization techniques, Wavelength Dispersive Spectroscopy (WDS) and X-ray Diffraction (XRD), respectively. To provide more detailed characterization of the materials' chemistry, we additionally employ a novel combinatorial synchrotron X-ray absorption near edge spectroscopy (XANES) technique. XANES is well-suited to characterize local chemical environments because the core-level excitations provide an element-specific, highly local probe of the unoccupied electronic structure, which is sensitive to local bonding. For example, $\mathrm{Ta}_{\mathrm{L}}$-edge XANES was used to characterize the covalency of Ta-O/N bonds in $(\mathrm{Ca}, \mathrm{Ba}, \mathrm{Sr}) \mathrm{TaO}_{2} \mathrm{~N} .{ }^{21}$ For the purpose of discovery of an oxynitride photoanode, wherein the nature of chemical incorporation of nitrogen is a critical descriptor, we investigate $\mathrm{N}$ K-edges in surface sensitive (total electron yield, TEY) and bulk sensitive (total fluorescence yield, TFY) modes using a custom combinatorial on-thefly scanning methodology. We investigate the optical properties of these compositions using custom high-throughput UV-Vis spectroscopy measurements, ${ }^{22}$ followed by band gap estimation using automated Tauc analysis. ${ }^{12 \mathrm{c}}$ By mapping the structure-chemistry-optical relationships on the $\mathrm{La}_{\mathrm{x}} \mathrm{Ta}_{1-\mathrm{x}} \mathrm{O}_{\mathrm{y}} \mathrm{N}_{\mathrm{z}}$ thin-film composition spread library, we reveal a substantial composition window over which phase-pure $\mathrm{LaTaON}_{2}$ is obtained and exhibits a consistent $2 \mathrm{eV}$ band gap. At La-rich compositions, the orthorhombic(orth)- $\mathrm{La}_{3} \mathrm{TaO}_{7}$ structure is obtained, and despite the 4.6 $\mathrm{eV}$ band gap reported ${ }^{20 \mathrm{~b}}$ for the stoichiometric oxide phase, visible absorption corresponding to a $2.2 \mathrm{eV}$ band gap is obtained through $\mathrm{N}_{2}$ intercalation.

\section{Experimental}

Figure 1 shows a schematic of the high-throughput synthesis and characterization workflow that enables rapid investigation of composition, crystal structure, and local chemical environment of multi-cation oxynitride libraries.

A thin film composition spread library of $\mathrm{La}_{x} \mathrm{Ta}_{1-\mathrm{x}} \mathrm{O}_{\mathrm{y}} \mathrm{N}_{\mathrm{z}}$ is synthesized by reactive cosputtering followed by RTP. Reactive co-sputtering proceeds in a custom-designed combinatorial sputtering system ${ }^{15}$ in a controllable $\mathrm{O}_{2} / \mathrm{N}_{2} / \mathrm{Ar}$ gas mixture. The library is deposited on a $100 \mathrm{~mm}$-diameter $\mathrm{Si}$ wafer (with approximately $170 \mathrm{~nm} \mathrm{SiO}{ }_{2}$ diffusion barrier) using $\mathrm{La}(99.9 \%$ purity) and $\mathrm{Ta}(99.95 \%$ purity) metal targets placed in magnetron sputtering cathodes located $120^{\circ}$ apart with respect to the plane of the $\mathrm{Si}$ wafer, at a distance of $2.14 \mathrm{~cm}$ from substrate center, and tilted $24^{\circ}$ towards the chamber center with respect to vertical. The deposition rate profiles of $\mathrm{La}$ and $\mathrm{Ta}$ as a function of $\mathrm{O}_{2}$ partial pressure (pp), with constant 0.2 $\mathrm{Pa} \mathrm{N}_{2}$ and $0.8 \mathrm{~Pa}$ total working gas pressure, shows that the deposition rate from both $\mathrm{La}$ and $\mathrm{Ta}$ sources decreases for $\mathrm{O}_{2}$ pp greater than $0.013 \mathrm{~Pa}$ (see Supporting Information (SI) Figure S1). 
This indicates that the sputtering process changes from sputtering of metal ions to sputtering of metal-oxide ions for $\mathrm{O}_{2} \mathrm{pp}$ beyond approximately $0.013 \mathrm{~Pa}$, motivating the use of $\mathrm{O}_{2} \mathrm{pp}$ less than $0.013 \mathrm{~Pa}$ as sputtered metal ions will be more reactive to $\mathrm{N}_{2}$ plasma compared to sputtered metaloxide ions. In this study, we choose an $\mathrm{O}_{2}$ pp of $4 \times 10^{-3} \mathrm{~Pa}$, which is maintained using a variable leak valve (Granville-Philips, series 203) providing $10^{-4} \mathrm{~Pa}$ precision. The La and Ta targets are pre-cleaned in the presence of $0.8 \mathrm{~Pa} \mathrm{Ar}$ for 10 minutes to remove any contaminants from the target surface. The deposition proceeded for 8 hours without any external substrate heating. The powers on the La and Ta sources are set to $100 \mathrm{~W} \mathrm{RF}$ and $81 \mathrm{~W}$ DC respectively to obtain the desired composition spread. The as-deposited $\mathrm{La}_{\mathrm{x}} \mathrm{Ta}_{1-\mathrm{x}} \mathrm{O}_{\mathrm{y}} \mathrm{N}_{\mathrm{z}}$ library is subsequently subject to $\mathrm{RTP}$ at $900^{\circ} \mathrm{C}$ for 30 seconds under flowing $\mathrm{N}_{2}$. To avoid anion exchange with the atmosphere in the RTP chamber, an atmosphere containing more than $99.9 \%$ pure $\mathrm{N}_{2}$ is obtained by purging the $9 \mathrm{~L}$ RTP chamber with $99.999 \%$ pure $\mathrm{N}_{2}$ at $13 \mathrm{lpm}$ for $240 \mathrm{~s}$. To reduce convective heat losses, a lower $\mathrm{N}_{2}$ flow rate of $3 \mathrm{lpm}$ is used during RTP, followed by an $\mathrm{N}_{2}$ flow rate of $13 \mathrm{lpm}$ during cool down. An image of the rectangular strip of interest after RTP is shown in Figure 1 (see SI Figure S2 for pre and post RTP images of the $100 \mathrm{~mm}$ library).

The bulk crystal structure of the $\mathrm{La}_{\mathrm{x}} \mathrm{Ta}_{1-\mathrm{x}} \mathrm{O}_{\mathrm{y}} \mathrm{N}_{\mathrm{z}}$ library is characterized by X-ray diffraction (XRD) using a Bruker DISCOVER D8 diffractometer with $\mathrm{Cu} \mathrm{K}_{\alpha}$ radiation from a Bruker $\mathrm{I} \mu \mathrm{S}$ source. Using a $0.5 \mathrm{~mm}$ collimator, the effective measurement area is approximately $0.5 \times 1 \mathrm{~mm}^{2}$. A series of XRD patterns are collected on samples with varying pitch to identify phase regions. For the compositions of interest, XRD patterns are collected at $<3$ at.\% spacing in the La cation fraction (x) using a two-dimensional VÅNTEC-500 detector and integrated into one-dimensional patterns using DIFFRAC.SUITE ${ }^{\mathrm{TM}}$ EVA software. The crystal structures present in each sample are identified by matching the XRD patterns with entries in the International Crystallography Diffraction Database (ICCD®).

The bulk cation and anion compositions are measured along the composition gradient with a $2 \mathrm{~mm}$ or smaller spacing using wavelength dispersive spectroscopy (WDS) on a JEOL 8200 electron microprobe instrument with a $10 \mathrm{keV}$ electron beam, $25 \mu \mathrm{A}$ beam current, and 10 $\mu \mathrm{m}$ beam size. Ta $\left(\mathrm{M}_{\alpha}\right)$ is measured using TAP crystal, $\mathrm{O}\left(\mathrm{K}_{\alpha}\right)$ and $\mathrm{N}\left(\mathrm{K}_{\alpha}\right)$ using LDE1 crystal, $\mathrm{La}\left(\mathrm{L}_{\alpha}\right)$ using PETL crystal. Tantalum metal, lanthanum phosphate, and gallium nitride are used to establish elemental standards. The measurement conditions are validated using a $\mathrm{TaON} / \mathrm{SiO}_{2} / \mathrm{Si}$ sample with similar thickness as the thin-film library of interest, and the composition is determined to be $\mathrm{Ta}_{0.33} \mathrm{O}_{0.33} \mathrm{~N}_{0.33}$ with no contribution observed from the substrate. Specific matrix effects are not accounted for, and a typical measurement error of $10 \%$ is assigned.

Optical characterization is performed using a custom-built on-the-fly HiTp instrument adapted for diffuse-reflectance $(D R)$ measurements (Figure 1) to analyze light absorber thin film libraries on opaque substrates. The software controlled setup uses a $220 \mathrm{~W} \mathrm{Hg}$ (Xe) lamp (Newport/Oriel Apex) and an integrating sphere (Ocean Optics ISP-50-8-R-GT) fiber-coupled to a spectrometer (Spectral Products, Inc. SM303), with details of the custom-built instrument adapted for simultaneous transmission and total reflectance provided by Mitrovic et al. ${ }^{22} \mathrm{DR}$ spectra are acquired on a square grid of 1521 positions with a $2.032 \mathrm{~mm}$ pitch, approximately 1 $\mathrm{mm}$ spot size, integration time of $25 \mathrm{~ms}$ per spectrum, and typically 3 spectra are averaged to produce the $D R$ spectrum for each sample. Direct-allowed Tauc Property spectra are obtained from the $D R$ spectra using Kubelka-Munk transformation. ${ }^{23}$

The chemistry of nitrogen incorporation is investigated using XANES measurements carried out at beamline 6.3.1 at the Advance Light Source (ALS) at Lawrence Berkeley National 
Laboratory (LBNL). ${ }^{24}$ The beam size at the sample is approximately $150 \times 400 \mu \mathrm{m}$. Hexagonal BN powder is used as a standard for the N K-edge energy region (390-550 eV) using the $1 s \rightarrow \pi^{*}$ transition at $401.65 \mathrm{eV}$. TFY and TEY signals are collected simultaneously, using a channel electron multiplier detector and a picoammeter monitoring drain current, respectively. Measurements are taken at room temperature under high vacuum around $1 \times 10^{-7} \mathrm{~Pa}$.

The unique soft X-ray combinatorial XANES capabilities at beamline 6.3.1 include automation of continuous monochromator energy scanning which reduces the time to measure across an absorption edge by one order of magnitude, ${ }^{25} \mathrm{x}-\mathrm{y}-\mathrm{z}$ sample translation, and simultaneous total electron yield (TEY) and total fluorescence yield (TFY) detection which enable surface and bulk XANES measurements across a $60 \times 100 \mathrm{~mm}^{2}$ region. The nominal speed of data acquisition for a $100 \mathrm{eV}$ spectral range is 2 minutes per TEY spectrum and 15 minutes per TFY spectrum. Spectra are normalized by the incoming beam intensity. As part of this work, an open-source graphic user interface called the XAS plug-in for Xi-CAM ${ }^{46}$ has been developed to automate pre-edge leveling and subtraction, normalization, and visualization of multiple spectra to streamline the work-flow for analyzing the hundreds of spectra typically measured using this technique. Along with this work a set of automated scripts have been developed to efficiently automate and visualize TEY and TFY spectra measured across a composition spread library. These measurements allow systematic study of anion chemical environment versus cation composition for multi-cation-multi-anion systems, an aspect that has not been previously well explored.

The resonant excitation of core-level electrons into unoccupied electronic states during XANES measurements results in core holes that are relaxed in various ways. Primary (photoelectrons), Auger, and secondary electrons are measured as an electrical current for TEY. $\mathrm{X}$-ray fluorescence generated from the relaxation of valence electrons to fill the core holes is measured as TFY. The probing depth for TEY is a function of the mean free path of the emitted electron which is typically less than $10 \mathrm{~nm}$ for soft X-rays. ${ }^{26}$ Thus TEY is considered to be a quasi-surface sensitive probe. In contrast, the probing depth of TFY is determined by the absorption length of X-ray photons in the sample, which in the soft X-ray regime is typically hundreds of nanometers. Thus TFY is considered a bulk sensitive probe. Simultaneous TEY and TFY detection of XANES on combinatorial oxynitride libraries enables us to investigate bulk and surface chemistry of oxynitrides with varying cation and anion compositions.

Since X-ray absorption edge jump is proportional to the number of absorbing atoms, $\mathrm{N}$ TFY edge jump can be used to capture semi-quantitative trends in bulk nitrogen content. ${ }^{27}$ To calculate the edge jump, the pre-edge value is calculated as the average of a linear regression fit that models the background from 388.6 to $396.3 \mathrm{eV}$, and the post-edge value is calculated as the average of the X-ray absorption values from 402.6 to $413.1 \mathrm{eV}$.

\section{Results and Discussions}

Due to the arrangement of the La and Ta sources in the deposition system, the material library can be considered as a pseudo-binary $\mathrm{La}_{\mathrm{x}} \mathrm{Ta}_{1-\mathrm{x}}$ composition library where lanthanum composition ' $x$ ' systematically increases from left to right of the thin film as shown in Figure 1. We observe that for the most La-rich compositions ( $x>0.75$ ), RTP induced significant film delamination, indicating that film adhesion was not sufficient to tolerate the RTP-induced stress. For $\mathrm{x}<0.58$, 
the compositions appeared metallic (see SI Figure S2) and no phase pure compositions were observed from initial XRD experiments, motivating our focus on the film region with $\mathrm{x} \in$ [0.58 - 0.75]. The range of colors observed from visual inspection of these thin film compositions includes yellow and red materials, indicating optical absorption of visible light and making this composition library an excellent candidate for detailed XRD, WDS, XANES, and UV-Vis characterization.

To visualize the phase behavior of the La-Ta-O-N materials, the background-subtracted XRD signals as a function of $x$ are mapped as a false color plot in Figure 2a. For compositions with $x \in[0.58-0.65]$, a single phase is observed with shifting Bragg diffraction peaks indicating lattice expansion with increasing $\mathrm{x}$. A second phase is observed to be phase pure (within the XRD detection limit) for $\mathrm{x} \in[0.72-0.75]$, and the intermediate $\mathrm{x} \in(0.65-0.72)$ compositions contain a mixture of these 2 phases. This phase behavior motivates the selection of 3 samples (A, B, and C) that correspond to the phase-pure regions at $\mathrm{x}=0.58,0.65$, and 0.72 respectively. Figure $2 \mathrm{~b}$ shows these representative XRD patterns along with the reference patterns used to identify the phases for samples $\mathrm{A}$ and $\mathrm{B}$ as $\mathrm{LaTaON}_{2}$ and sample $\mathrm{C}$ as orthorhombic $\mathrm{La}_{3} \mathrm{TaO}_{7}$ (orth- $\mathrm{La}_{3} \mathrm{TaO}_{7}$ ).

Figure 3 shows the variation of anion compositions per unit cation ( $y$ for oxygen and $z$ for nitrogen in $\mathrm{La}_{\mathrm{x}} \mathrm{Ta}_{1-\mathrm{x}} \mathrm{O}_{\mathrm{y}} \mathrm{N}_{\mathrm{z}}$ ) as a function of the lanthanum cation fraction (x). For the $\mathrm{LaTaON}_{2}$ phase region, $\mathrm{x} \in[0.58-0.65]$, y and $\mathrm{z}$ remain fairly constant at $1.6 \pm 0.1$ and $0.26 \pm 0.03$, respectively. As $x$ increases from 0.65 to 0.72 through the two-phase region, $y$ steadily increases and $\mathrm{z}$ steadily decreases, reaching values of approximately 0.3 and 0.04 respectively in the orth- $\mathrm{La}_{3} \mathrm{TaO}_{7}$ phase region. As highlighted in Table 1, the O:N stoichiometry in the $\mathrm{LaTaON}_{2}$ thin films are more than a factor of 10 higher than that of the formula unit. This demonstration that $\mathrm{LaTaON}_{2}$ can be made O-rich and N-poor is important for electrochemical applications as the oxidation resistance and electrochemical stability of this perovskite phase are likely enhanced by these departures from the phase's formula unit stoichiometry. ${ }^{28}$ The $\mathrm{LaTaON}_{2}$ thin films are substantially La-rich, which appears to enable the increased O:N under the assumption that $\mathrm{Ta}, \mathrm{La}, \mathrm{O}$ and $\mathrm{N}$ remain in $+5,+3,-2$ and -3 oxidation states, respectively. Using these oxidation states, the ratio of the total anion charge to total cation charge averaged over the WDS measurements in the $\mathrm{LaTaON}_{2}$ phase region is $1.05 \pm 0.1$, demonstrating charge balance within measurement uncertainty. The increase in lattice constant with increased La cation fraction is also commensurate with the higher ionic radius of $\mathrm{La}^{+3}$ compared to $\mathrm{Ta}^{+5} ;{ }^{29}$ although the structural details of the cation and anion substitutions are not well-characterized by the present XRD analysis and must additionally consider vacancy concentrations, as discussed further below. This combinatorial alloying study is the first demonstration of accessing large degrees of freedom in both cation and anion compositions within a given oxyntride phase synthesis, and perhaps for the synthesis of any material, highlighting the utility of the PVD-RTP approach in exploring multi-cation-multi-anion composition spaces.

We now discuss the optical properties across the composition region of interest. Figure $4 \mathrm{a}$ shows the direct-allowed Tauc plots of representative compositions for $x \in(0.58-0.75)$. The Tauc spectra are scaled by their maximum value for ease of representation (see SI Figure S3 for unscaled absorption spectra). For $\mathrm{x} \in(0.58-0.65)$, a band gap of approximately $2.0 \mathrm{eV}$ is observed, and is an excellent match to the reported literature value for the stoichiometric $\mathrm{LaTaON}_{2}$ phase. ${ }^{17}$ That is, despite the presence of significantly sub-stoichiometric nitrogen content for these compositions, the nitrogen content appears to be sufficient to introduce the same band-to-band shift of optical absorption as the stoichiometric perovskite $\mathrm{LaTaON}_{2}$ phase. 
For $\mathrm{x}=0.72$, with a predomoninantly orth $-\mathrm{La}_{3} \mathrm{TaO}_{7}$ phase, we observe a band gap of $2.2 \mathrm{eV}$, a significant decrease from the $4.6 \mathrm{eV}$ band gap reported by Abe et al. for stoichiometric orth$\mathrm{La}_{3} \mathrm{TaO}_{7}{ }^{20 \mathrm{~b}}$ For higher La cation fraction up to 0.75 , no optical transition corresponding to band gap is observed within the spectrometer range (1.3-3.5 eV). To confirm that the presence of nitrogen is responsible for the decreased band gap at $\mathrm{x}=0.72$, we synthesized a La-Ta-O composition spread thin film library via reactive co-sputtering in the presence of oxygen as the reactive gas (nitrogen was not introduced) followed by RTP (see SI Figure S4 for the library image). The ensuing optical characterization of the orth $-\mathrm{La}_{3} \mathrm{TaO}_{7}$ thin films revealed that nitrogen is required for obtaining the $2.2 \mathrm{eV}$ band gap feature of Fig. 4a (see SI Figure S5).

We examine the nitrogen chemistry in these thin films by visualizing the XANES spectra of the N K-edge (Figure 5) between 395 and $410 \mathrm{eV}$. For Figure 5 we level at the N K-pre-edge and normalize to the $\mathrm{La} \mathrm{M}_{5}$ white line intensity for ease of viewing. The $\mathrm{La} \mathrm{M}_{4,5}$-edge can conveniently be recorded in the same dataset because the monochromator provides some amount of second order diffracted light with twice the nominal photon energy. Surface sensitive (TEY) XANES measurements indicate the presence of nitrogen in the $\mathrm{LaTaON}_{2}$ phase region, while nitrogen was not observed for the $\mathrm{La}_{3} \mathrm{TaO}_{7}$ phase region (see SI Figure S6). Bulk-sensitive (TFY) XANES spectra at the N K-edge reveal the presence of nitrogen in all samples. Figure S7 shows excellent qualitative agreement between the trends of relative N TFY edge jump and nitrogen composition obtained from WDS, as a function of cation composition. Where, the relative N TFY edge jump is obtained by scaling the edge jump by its' maximum value in the composition spread library. The presence of nitrogen in both surface and bulk in the $\mathrm{LaTaON}_{2}$ phase region compared to the presence of nitrogen only in bulk $\mathrm{La}_{3} \mathrm{TaO}_{7}$ indicates a difference in the chemical environment of nitrogen in these two phases. The formation of an oxide surface layer in $\mathrm{La}_{3} \mathrm{TaO}_{7}$, possibly via displacement of $\mathrm{N}$ by $\mathrm{O}$ either upon air exposure or during the RTP processing, is consistent with earlier demonstrations that oxynitrides are typically passivated by oxide and/or oxy-hydroxide surface layers. ${ }^{30}$ We now examine the TFY N K-edge features of representative samples to understand the chemical environment of nitrogen in both these phases.

Figure 6 shows the TFY spectra of N K-edge for the samples A, B, and C along with reference spectra collected for $\beta$-TaON. We observe that the $\mathrm{N}$-features for samples $\mathrm{A}$ and $\mathrm{B}$ are similar to $\beta-\mathrm{TaON}$, indicating that La may not play a significant role in the local chemical environment of $\mathrm{N}$ for these samples. Indeed, from the crystal structure of stoichiometric $\mathrm{LaTaON}_{2}$ phase ( ICDD ${ }^{\circledR}$ PDF Card: 01-070-5267), the shortest La-N bond length is $2.68 \AA$ and the shortest Ta-N bond length is $1.46 \AA$ (Figure S8), which also points to smaller influence of $\mathrm{La}$ on the $\mathrm{N}$ chemical environment. The indication that the $\mathrm{N}$ chemical environment does not substantially differ from that of $\beta$-TaON over the range of thin film compositions supports the above-noted conclusion from optical measurements that the $\mathrm{N}$-induced band-to-band shifting and $2.0 \mathrm{eV}$ band gap are unaffected by the $\mathrm{O}: \mathrm{N}$ ratio being 10 times higher in our samples compared to the stoichiometric phase. Note that earlier studies of optical properties of oxynitrides as a function of nitrogen content with stoichiometric cation fraction have shown the need for presence of nearly stoichiometric nitrogen to introduce band-to-band shifting. ${ }^{31}$ Thus, our work highlights the importance of simultaneous variation of cation and anion fraction for discovery of substoichiometric phases with the desired optical properties. We hypothesize that as the La:Ta ratio increases beyond 1, charge neutrality is maintained by balancing Ta vacancy 
formation with $\mathrm{O}$ substitution on $\mathrm{N}$-sites. For the most La-rich composition with the perovskite structure, which is sample $\mathrm{B}$ with $\mathrm{x}=0.65,46 \%$ of the Ta sites are vacant under the assumption of $100 \%$ La occupancy on the La site and no La substitions on Ta sites. Vacancy numbers of this magnitude are quite rare among solid state materials and in particular oxides. A model was recently developed to predict the maximum vacancy concentrations for a cation or anion site in perovskite oxides, with much lower maximum vacancy numbers predicted over a wide range of material systems. ${ }^{32}$ For oxynitride perovskites, charge balancing through concomitant anion and cation defects (substitutions and/or vacancies) accommodates much higher compositional variation within a given crystal structure, creating increased opportunity for tailoring materials properties for the target application. For example, the lower nitrogen content in our oxynitride samples likely improves aqueous stability compared to the stoichiometric phase, particularly stability against chemical or electrochemical oxidation. ${ }^{28}$

For the orth- $\mathrm{La}_{3} \mathrm{TaO}_{7}$ sample, the $\mathrm{N} \mathrm{K}$-edge signal is substantially different than that from the oxyntride crystal structures. Figure 6 sample $\mathrm{C}$ displays the orth- $\mathrm{La}_{3} \mathrm{TaO}_{7}$ phase with a single peak at $401 \mathrm{eV}$ corresponding to the $1 s \rightarrow \pi^{*}$ transition of diatomic nitrogen $\left(\mathrm{N}_{2}\right){ }^{33} \mathrm{~N}_{2}$ intercalation into metal oxide lattices has been previously reported for few phases. ${ }^{6,34}$ The $\mathrm{WO}_{3}: \mathrm{N}_{2}$ example comprises a well-studied solar fuels photoanode wherein the lattice distortions induced by the intercalated $\mathrm{N}_{2}$ lead to changes in the geometry of the $\mathrm{WO}_{6}$ octahedra. This significantly lowers the conduction band edge energy dominated by the $\mathrm{W} 5 \mathrm{~d}-\mathrm{O} 2 \mathrm{p} \pi *$ orbitals and slightly increases the valence band edge energy due to the contribution of $\mathrm{N} 2 \mathrm{p}$ orbitals. The result is a $0.7 \mathrm{eV}$ reduction in band gap energy for intercalation of $0.039 \mathrm{~N}_{2}$ molecules per formula unit of $\mathrm{WO}_{3}$. In the case of $\mathrm{N}_{2}$ intercalated $\mathrm{La}_{3} \mathrm{TaO}_{7}\left(\mathrm{La}_{3} \mathrm{TaO}_{7}: \mathrm{N}_{2}\right)$ the observation of the $2.2 \mathrm{eV}$ direct-allowed band gap energy in Figure 4, is consistent with the orange-yellow appearance of the thin film as in Figure 1. $\mathrm{N}_{2}$ intercalation on the order of 0.08 molecules per formula unit lowers the band gap energy of $\mathrm{La}_{3} \mathrm{TaO}_{7}$ by approximately $2.4 \mathrm{eV}$.

Figure $\mathrm{S} 9$ illustrates possible locations for $\mathrm{N}_{2}$ intercalation in $\mathrm{La}_{3} \mathrm{TaO}_{7}$ based on identification of the most likely interstitial sites from free volume considerations. Further experimental and computational characterizations of $\mathrm{La}_{3} \mathrm{TaO}_{7}: \mathrm{N}_{2}$ are required to identify the geometry of $\mathrm{N}_{2}$ intercalation and elucidate the electronic underpinnings of the visible absorption. While the optical attenuation coefficient cannot be determined from the $D R$ measurements due to the unkown diffuse scattering efficiency and the expectation that the thin film is not optically dense, Figure $\mathrm{S} 3$ suggests that the $\mathrm{La}_{3} \mathrm{TaO}_{7}: \mathrm{N}_{2}$ thin film is less absorbing than the materials corresponding to the $\mathrm{LaTaON}_{2}$ phase region,suggesting future studies to enhance absorption via increased $\mathrm{N}_{2}$ intercalation. The Materials Project ${ }^{35}$ Pourbaix App ${ }^{36}$ predicts that $\mathrm{La}_{3} \mathrm{TaO}_{7}$ is electrochemically stable for all $\mathrm{pH}$ in excess of 11.5 and potentials from $-1 \mathrm{~V}$ to above $3 \mathrm{~V}$ vs RHE straddling oxygen evolution and hydrogen evolution reaction potentials (see SI Figure S10). The remarkable electrochemical stability window of this phase and the demonstrated stability of $\mathrm{N}_{2}$ molecules in $\mathrm{WO}_{3}$ under photoelectrochemical conditions ${ }^{37}$ makes the discovery of visible absorption via $\mathrm{N}_{2}$ intercalation important for solar photochemical applications. While the Pourbaix stability indicates that these materials may be operationally stable solar fuels photoelectrode materials, the photoelectrochemical activity is not assessed in the present work due to the lack of a conductive back contact to the thin film materials.

\section{Conclusions}

By combining a suite of combinatorial thin film synthesis and characterization techniques, we identify two distinct optical phenomena of La-Ta-O-N thin films. By synthesizing La and O-rich 
(Ta and $\mathrm{N}$-poor) variants of the $\mathrm{LaTaON}_{2}$ perovskite structure, a $2.0 \mathrm{eV}$ direct-allowed band gap is obtained over a substantial composition range. This remarkable decoupling of the band gap energy with both cation stoichiometry and anion stoichiometry creates ample opportunity to optimize the composition of this solar fuels light absorber with respect to electrochemical stability, carrier transport, and catalytic activity. At more La-rich compositions the deposition and then crystallization of $\mathrm{La}_{3} \mathrm{TaO}_{7}$ in the presence of $\mathrm{N}_{2}$ led to intercalation of $\mathrm{N}_{2}$ on the order of 0.08 molecules per formula unit resulting in a remarkable $2.4 \mathrm{eV}$ red-shift in optical absorption. Combined with the excellent electrochemical stability of the parent oxide phase, $\mathrm{La}_{3} \mathrm{TaO}_{7}: \mathrm{N}_{2}$ is a promising light absorber for solar fuels applications.

\section{Acknowledgements}

This study is based upon work performed by the Joint Center for Artificial Photosynthesis, a DOE Energy Innovation Hub, supported through the Office of Science of the U.S. Department of Energy (Award No. DE-SC0004993). The authors thank Dr. Chi Ma and Prof. George R. Rossman for assistance with WDS measurements. This research used resources of the Advanced Light Source, which is a DOE Office of Science User Facility under contract no. DE-AC0205CH11231. The authors also thank Yi-Sheng Liu, Li Cheng Kao, and Yifan Ye for assistance with XANES measurements at ALS beamline 6.3.1.2.

Supporting Information: Deposition details; Images of thin film library with and without nitrogen and with and without RTP; Additional optical, composition, and XAS characterization; Crystal structure models; La-Ta Pourbaix diagram.

\section{References}

1. (a) Lu, D.; Kondo, J. N.; Hara, M.; Takata, T.; Domen, K., Systematical investigation on characteristics of a photocatalyst: tantalum oxynitrides. Microscopy 2014, 63 (4), 313-324; (b) de Respinis, M.; Fravventura, M.; Abdi, F. F.; Schreuders, H.; Savenije, T. J.; Smith, W. A.; Dam, B.; van de Krol, R., Oxynitrogenography: Controlled Synthesis of Single-Phase Tantalum Oxynitride Photoabsorbers. Chemistry of Materials 2015, 27 (20), 7091-7099.

2. (a) Siritanaratkul, B.; Maeda, K.; Hisatomi, T.; Domen, K., Synthesis and Photocatalytic Activity of Perovskite Niobium Oxynitrides with Wide Visible-Light Absorption Bands. Chemsuschem 2011, 4 (1), 7478; (b) Moriya, Y.; Takata, T.; Domen, K., Recent progress in the development of (oxy)nitride photocatalysts for water splitting under visible-light irradiation. Coordin Chem Rev 2013, 257, 19571969.

3. (a) Wu, Y.; Lazic, P.; Hautier, G.; Persson, K.; Ceder, G., First principles high throughput screening of oxynitrides for water-splitting photocatalysts. Energ Environ Sci 2013, 6 (1), 157-168; (b) Castelli, I. E.; Landis, D. D.; Thygesen, K. S.; Dahl, S.; Chorkendorff, I.; Jaramillo, T. F.; Jacobsen, K. W., New cubic perovskites for one- and two-photon water splitting using the computational materials repository. Energ Environ Sci 2012, 5 (10), 9034-9043.

4. Pan, C.; Takata, T.; Nakabayashi, M.; Matsumoto, T.; Shibata, N.; Ikuhara, Y.; Domen, K., A complex perovskite-type oxynitride: the first photocatalyst for water splitting operable at up to $600 \mathrm{~nm}$. Angewandte Chemie 2015, 54 (10), 2955-9.

5. (a) Takata, T.; Hitoki, G.; Kondo, J. N.; Hara, M.; Kobayashi, H.; Domen, K., Visible-light-driven photocatalytic behavior of tantalum-oxynitride and nitride. Research on Chemical Intermediates 2007, 33 (1-2), 13-25; (b) Cong, Y.; Park, H. S.; Wang, S.; Dang, H. X.; Fan, F.-R. F.; Mullins, C. B.; Bard, A. J., Synthesis of Ta3N5Nanotube Arrays Modified with Electrocatalysts for Photoelectrochemical Water 
Oxidation. The Journal of Physical Chemistry C 2012, 116 (27), 14541-14550; (c) Dabirian, A.; Spijker, H. v. t.; van de Krol, R., Wet ammonia Synthesis of Semiconducting N:Ta2O5, Ta3N5 and $\beta$-TaON Films for Photoanode Applications. Energy Procedia 2012, 22, 15-22; (d) Swisher, J. H.; Read, M. H., Thermodynamic properties and electrical conductivity of Ta3N5 and TaON. Metallurgical Transactions 1972, 3 (2), 493-498; (e) Kerlau, M.; Merdrignac-Conanec, O.; Guilloux-Viry, M.; Perrin, A., Synthesis of crystallized TaON and Ta3N5 by nitridation of Ta2O5 thin films grown by pulsed laser deposition. Solid State Sciences 2004, 6 (1), 101-107; (f) Matizamhuka, W. R.; Sigalas, I.; Herrmann, M., Synthesis, sintering and characterisation of TaON materials. Ceramics International 2008, 34 (6), 1481-1486; (g) Chen, S.; Wang, L.-W., Intrinsic defects and electronic conductivity of TaON: First-principles insights.

Appl Phys Lett 2011, 99 (22), 222103; (h) Dabirian, A.; van de Krol, R., High-Temperature Ammonolysis of Thin Film Ta2O5Photoanodes: Evolution of Structural, Optical, and Photoelectrochemical Properties. Chemistry of Materials 2015, 27 (3), 708-715.

6. $\quad$ Ebbinghaus, S. G.; Abicht, H.-P.; Dronskowski, R.; Mueller, T.; Reller, A.; Weidenkaff, A., Perovskite-related oxynitrides - Recent developments in synthesis, characterisation and investigations of physical properties. Progress in Solid State Chemistry 2009, 37 (2-3), 173-205.

7. Dupuis, J.; Fourmond, E.; Ballutaud, D.; Bererd, N.; Lemiti, M., Optical and structural properties of silicon oxynitride deposited by plasma enhanced chemical vapor deposition. Thin Solid Films 2010, 519, 1325-1333.

8. Kim, Y.-I.; Paik, Y.; Avdeev, M., Intercalation Route to Complex Perovskites AM 0.2 Ta 0.8 O $2.8 \mathrm{~N}$ 0.2 (A = Sr, Ba; M = Li, Na): Neutron Diffraction and Nuclear Magnetic Resonance Study. Crystal Growth \& Design 2014, 141209134411000.

9. Laurikaitis, M.; Dudonis, J.; Milčius, D., Deposition of zirconium oxynitride films by reactive cathodic arc evaporation and investigation of physical properties. Thin Solid Films 2008, 516, 1549-1552.

10. Takata, T.; Pan, C.; Domen, K., Design and Development of Oxynitride Photocatalysts for Overall Water Splitting under Visible Light Irradiation. ChemElectroChem 2016, 3 (1), 31-37.

11. Higashi, M.; Domen, K.; Abe, R., Fabrication of efficient TaON and Ta3N5 photoanodes for water splitting under visible light irradiation. Energ Environ Sci 2011, 4 (10), 4138.

12. (a) Suram, S. K.; Xue, Y.; Bai, J.; Le Bras, R.; Rappazzo, B.; Bernstein, R.; Bjorck, J.; Zhou, L.; van Dover, R. B.; Gomes, C. P.; Gregoire, J. M., Automated Phase Mapping with AgileFD and its Application to Light Absorber Discovery in the V-Mn-Nb Oxide System. ACS Comb. Sci. 2017, 19 (1), 37-46; (b) Suram, S. K.; Newhouse, P. F.; Zhou, L.; Van Campen, D. G.; Mehta, A.; Gregoire, J. M., High Throughput Light Absorber Discovery, Part 2: Establishing Structure-Band Gap Energy Relationships. ACS Comb. Sci. 2016, 18 (11), 682-688; (c) Suram, S. K.; Newhouse, P. F.; Gregoire, J. M., High Throughput Light Absorber Discovery, Part 1: An Algorithm for Automated Tauc Analysis. ACS Comb. Sci. 2016, 18 (11), 673-681; (d) Shinde, A.; Li, G.; Zhou, L.; Guevarra, D.; Suram, S. K.; Toma, F. M.; Yan, Q.; Haber, J. A.; Neaton, J. B.; Gregoire, J. M., The role of the CeO2/BiVO4interface in optimized Fe-Ce oxide coatings for solar fuels photoanodes. J. Mater. Chem. A 2016, 4 (37), 14356-14363; (e) Guevarra, D.; Shinde, A.; Suram, S. K.; Sharp, I. D.; Toma, F. M.; Haber, J. A.; Gregoire, J. M., Development of solar fuels photoanodes through combinatorial integration of $\mathrm{Ni}$-La-Co-Ce oxide catalysts on BiVO4. Energy Environ. Sci. 2016, 9 (2), 565580.

13. (a) Yan, Q.; Yu, J.; Suram, S. K.; Zhou, L.; Shinde, A.; Newhouse, P. F.; Chen, W.; Li, G.; Persson, K. A.; Gregoire, J. M.; Neaton, J. B., Solar fuels photoanode materials discovery by integrating highthroughput theory and experiment. Proc Natl Acad Sci U S A 2017, 114 (12), 3040-3043; (b) Newhouse, P. F.; Boyd, D. A.; Shinde, A.; Guevarra, D.; Zhou, L.; Soedarmadji, E.; Li, G.; Neaton, J. B.; Gregoire, J. M., Solar fuel photoanodes prepared by inkjet printing of copper vanadates. J. Mater. Chem. A 2016, 4 (19), 7483-7494; (c) Zhou, L.; Yan, Q.; Shinde, A.; Guevarra, D.; Newhouse, P. F.; Becerra-Stasiewicz, N.; Chatman, S. M.; Haber, J. A.; Neaton, J. B.; Gregoire, J. M., High Throughput Discovery of Solar Fuels Photoanodes in the CuO-V2O5 System. Adv. En. Mater. 2015, 5 (22), 1500968; (d) Yan, Q.; Li, G.; 
Newhouse, P. F.; Yu, J.; Persson, K. A.; Gregoire, J. M.; Neaton, J. B., Mn2V2O7: An Earth Abundant Light Absorber for Solar Water Splitting. Adv En Mater 2015, 5 (8), 1401840.

14. (a) Martin-Litas, I.; Vinatier, P.; Levasseur, A.; Dupin, J. C.; Gonbeau, D.; Weill, F., Characterisation of r.f. sputtered tungsten disulfide and oxysulfide thin films. Thin Solid Films 2002, 416 (1-2), 1-9; (b) Hänninen, T.; Schmidt, S.; Jensen, J.; Hultman, L.; Högberg, H., Silicon oxynitride films deposited by reactive high power impulse magnetron sputtering using nitrous oxide as a single-source precursor. Journal of Vacuum Science \& Technology A: Vacuum, Surfaces, and Films 2015, 33 (5), $05 \mathrm{E} 121$.

15. Zhou, L.; Suram, S. K.; Becerra-Stasiewicz, N.; Mitrovic, S.; Kan, K.; Jones, R. J. R.; Gregoire, J. M., Combining reactive sputtering and rapid thermal processing for synthesis and discovery of metal oxynitrides. Journal of Materials Research 2015, 30 (19), 2928-2933.

16. (a) Mohamed, S. H.; Abd El-Rahman, a. M.; Ahmed, M. R., Investigation of zirconium oxynitride thin films deposited by reactive pulsed magnetron sputtering. Journal of Physics D: Applied Physics 2007, 40, 7057-7062; (b) Mohamed, S. H.; Kappertz, O.; Ngaruiya, J. M.; Niemeier, T.; Drese, R.; Detemple, R.; Wakkad, M. M.; Wuttig, M., Influence of nitrogen content on properties of direct current sputtered TiOxNy films. Phys Status Solidi A 2004, 201 (1), 90-102.

17. Maeda, K.; Domen, K., New Non-Oxide Photocatalysts Designed for Overall Water Splitting under Visible Light. Journal of Physical Chemistry C 2007, 111, 7851-7861.

18. Hu, S.; Xiang, C.; Haussener, S.; Berger, A. D.; Lewis, N. S., An analysis of the optimal band gaps of light absorbers in integrated tandem photoelectrochemical water-splitting systems. Energ Environ Sci 2013, 6 (10), 2984.

19. Singh, M. R.; Clark, E. L.; Bell, A. T., Thermodynamic and achievable efficiencies for solar-driven electrochemical reduction of carbon dioxide to transportation fuels. Proc Natl Acad Sci U S A 2015, 112 (45), E6111-8.

20. (a) Abe, R.; Higashi, M.; Zou, Z.; Sayama, K.; Abe, Y.; Arakawa, H., Photocatalytic Water Splitting into H2and O2over R3TaO7and R3NbO7(R $=Y, Y b, G d, L a)$ : Effect of Crystal Structure on Photocatalytic Activity. The Journal of Physical Chemistry B 2004, 108 (3), 811-814; (b) Abe, R.; Higashi, M.; Sayama, K.; Abe, Y.; Sugihara, H., Photocatalytic activity of R3MO7 and R2Ti2O7 ( $R=Y, G d, L a ; M=N b, T a)$ for water splitting into $\mathrm{H} 2$ and O2. J Phys Chem B 2006, 110 (5), 2219-26.

21. Paek, S.-M.; Kim, Y.-I., Ta L-3-edge XANES study of perovskite oxynitrides $\mathrm{ATaO}(2) \mathrm{N}(\mathrm{A}=\mathrm{Ca}$, Sr, Ba). Journal of Alloys and Compounds 2014, 587, 251-254.

22. Mitrovic, S.; Cornell, E. W.; Marcin, M. R.; Jones, R. J.; Newhouse, P. F.; Suram, S. K.; Jin, J.; Gregoire, J. M., High-throughput on-the-fly scanning ultraviolet-visible dual-sphere spectrometer. The Review of scientific instruments 2015, 86 (1), 013904.

23. Kubelka, P., New Contributions to the Optics of Intensely Light-Scattering Materials Part I. Journal of the Optical Society of America 1948, 38 (5), 448.

24. Nachimuthu, P.; Underwood, J. H.; Kemp, C. D.; Gullikson, E. M.; Lindle, D. W.; Shuh, D. K.; Perera, R. C., Performance Characteristics of Beamline 6.3.1 from $200 \mathrm{eV}$ to $2000 \mathrm{eV}$ at the Advanced Light Source. Proceedings of the Eighth International Conference on Synchrotron Radiation Instrumentation 2004, 705, 454-457. American Institute of Physics.

25. Lin, S.-W.; Chang, C.-F.; Lee, R.; Huang, C.-Y.; Ma, C.-I.; Fan, L.-J.; Fung, H.-S., On-the-fly Scan: Improving the Performance of Absorption Spectrum Measurement. Journal of Physics: Conference Series 2013, 425 (12), 122002.

26. Frazer, B. H.; Gilbert, B.; Sonderegger, B. R.; De Stasio, G., The probing depth of total electron yield in the sub-keV range: TEY-XAS and X-PEEM. Surface Science 2003, 537 (1-3), 161-167.

27. Osawa, T., Quantitative Estimation Methods for Concentrations and Layer Thicknesses of Elements Using Edge-jump Ratios of X-ray Absorption Spectra. Analytical Sciences 2010, 26 (2), 281-284. 
28. Castelli, I. E.; Thygesen, K. S.; Jacobsen, K. W., Calculated Pourbaix Diagrams of Cubic Perovskites for Water Splitting: Stability Against Corrosion. Topics in Catalysis 2013, 57 (1-4), 265-272.

29. Shanon, R. D., Revised Effective Ionic Radii and Systematic Studies of Interatomie Distances in Halides and Chaleogenides. Acta Crystallographica 1976, A32, 751-767.

30. Kim, Y.--.; Paik, Y., Bond covalency in perovskite oxynitrides $\mathrm{ATaO}(2) \mathrm{N}(\mathrm{A}=\mathrm{Ca}, \mathrm{Sr}, \mathrm{Ba})$ studied by N-14 NMR spectroscopy. Solid State Sciences 2012, 14 (5), 580-582.

31. (a) Aguiar, R.; Kalytta, A.; Reller, A.; Weidenkaff, A.; Ebbinghaus, S. G., Photocatalytic decomposition of acetone using $\operatorname{LaTi}(\mathrm{O}, \mathrm{N}) 3$ nanoparticles under visible light irradiation. Journal of Materials Chemistry 2008, 18 (36), 4260; (b) Marozau, I.; Shkabko, A.; Döbeli, M.; Lippert, T.;

Logvinovich, D.; Mallepell, M.; Schneider, C. W.; Weidenkaff, A.; Wokaun, A., Optical Properties of Nitrogen-Substituted Strontium Titanate Thin Films Prepared by Pulsed Laser Deposition. Materials 2009, 2 (3), 1388-1401; (c) Mohamed, S. H.; Anders, A., Structural, optical, and electrical properties of WOx(Ny) films deposited by reactive dual magnetron sputtering. Surface and Coatings Technology 2006, 201 (6), 2977-2983.

32. Ji, D. H.; Wang, S. L.; Ge, X. Z.; Zhang, Q. Q.; Zhang, C. M.; Zeng, Z. W.; Bai, Y., The maximum predicted content of cation vacancies in inorganic and organic-inorganic perovskites: the role of the tolerance factor. Phys Chem Chem Phys 2017, 19 (26), 17121-17127.

33. Gillespie, A. W.; Walley, F. L.; Farrell, R. E.; Regier, T. Z.; Blyth, R. I., Calibration method at the N $\mathrm{K}$-edge using interstitial nitrogen gas in solid-state nitrogen-containing inorganic compounds. Journal of synchrotron radiation 2008, 15 (Pt 5), 532-4.

34. (a) Rachel, a.; Ebbinghaus, S. G.; Güngerich, M.; Klar, P. J.; Hanss, J.; Weidenkaff, a.; Reller, a., Tantalum and niobium perovskite oxynitrides: Synthesis and analysis of the thermal behaviour.

Thermochimica Acta 2005, 438, 134-143; (b) Tessier, F.; Le Gendre, L.; Cheviré, F.; Marchand, R.; Navrotsky, A., Thermochemistry of a New Class of Materials Containing Dinitrogen Pairs in an Oxide Matrix. Chemistry of Materials 2005, 17 (13), 3570-3574; (c) Le Gendre, L.; Marchand, R.; Piriou, B., Raman scattering investigations of dinitrogen entities in oxidized LaTiO2N perovskite. Eur J Sol State Inor 1997, 34 (9), 973-982.

35. Jain, A.; Ong, S. P.; Hautier, G.; Chen, W.; Richards, W. D.; Dacek, S.; Cholia, S.; Gunter, D.; Skinner, D.; Ceder, G.; Persson, K. A., Commentary: The Materials Project: A materials genome approach to accelerating materials innovation. APL Materials 2013, 1, 011002.

36. Persson, K. A.; Waldwick, B.; Lazic, P.; Ceder, G., Prediction of solid-aqueous equilibria: Scheme to combine first-principles calculations of solids with experimental aqueous states. Phys. Rev. B 2012, 85 (23), 235438.

37. Mi, Q.; Ping, Y.; Li, Y.; Cao, B.; Brunschwig, B. S.; Khalifah, P. G.; Galli, G. A.; Gray, H. B.; Lewis, N. $\mathrm{S}$., Thermally stable N2-intercalated WO3 photoanodes for water oxidation. Journal of the American Chemical Society 2012, 134 (44), 18318-24.

\section{Figures}




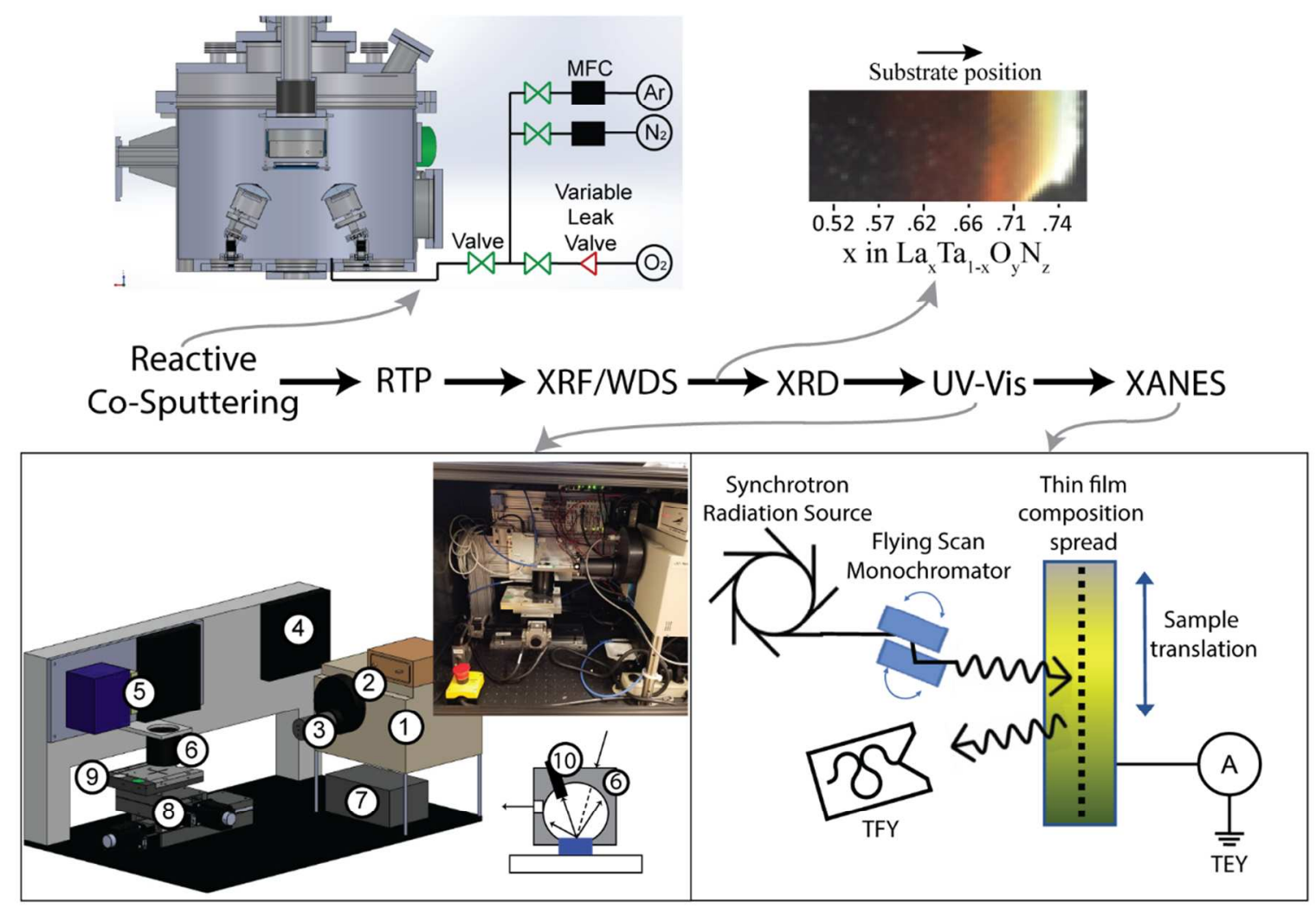

Figure 1. A schematic of the high-throughput synthesis and characterization workflow to investigate composition and structure of oxynitride materials. The UV-Vis components are 1. light source, 2. shutter and controller, 3. fiber coupling lens system, 4. stage controllers, 5. communication controllers, 6 . integrating sphere, 7. spectrometer, 8. translation stage, 9. vacuum chuck, and 10. specular reflection absorbing plug. In the combinatorial XANES experiment, Total Electron Yield (TEY) is detected using an ammeter, and Total Fluorescence Yield (TFY) is detected using a channel electron multiplier. 

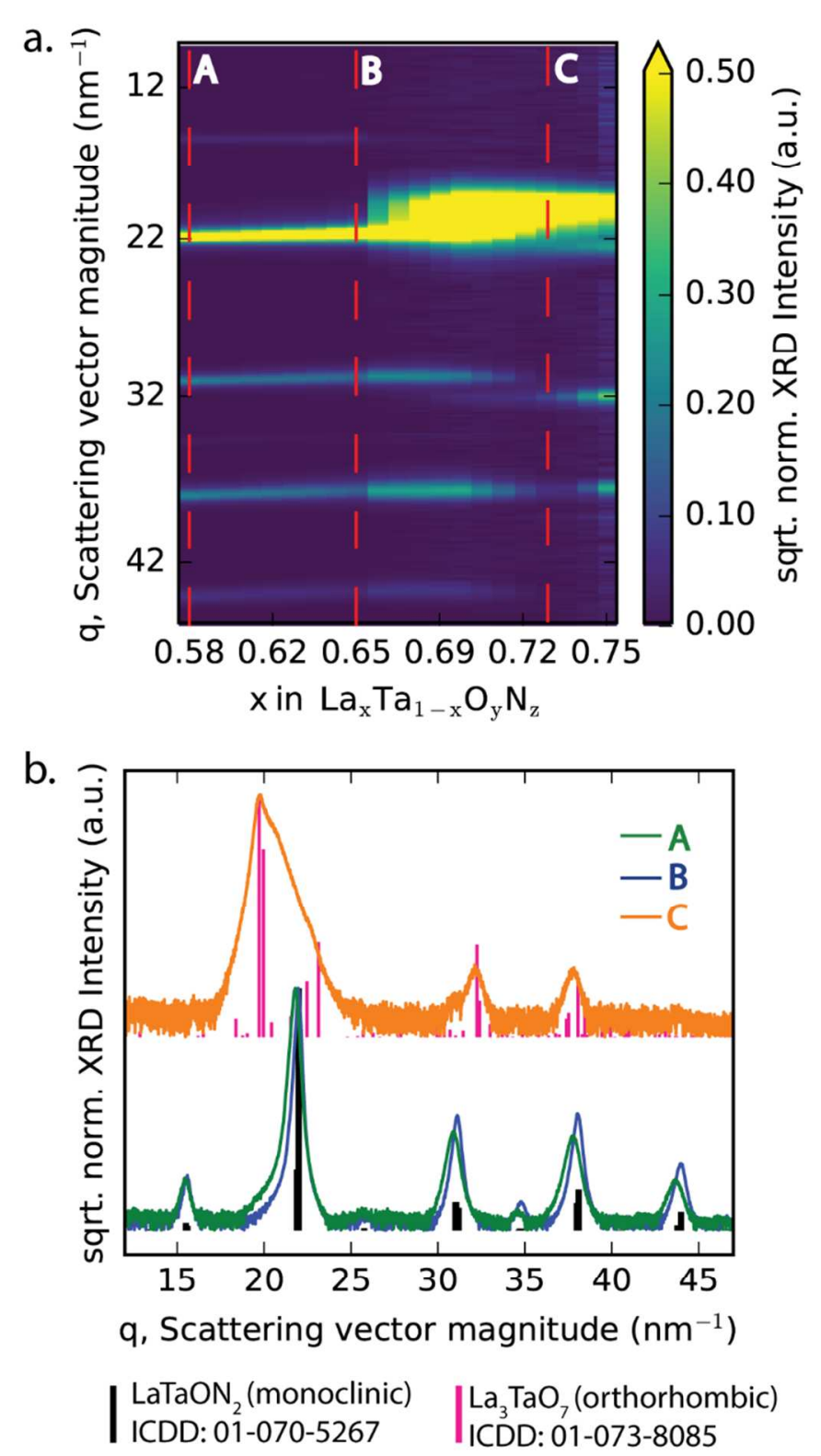

Figure 2. a) False color map of square root of background-subtracted XRD intensity as a function of La cation fraction (x), b) XRD patterns for samples A, B and C (see Table 1 for compositions) with stick patterns of the corresponding ICDD patterns. For both phases and especially the $\mathrm{La}_{3} \mathrm{TaO}_{7}$ material, the small grain size and possibly the disorder in the thin film samples precludes resolution of neighboring diffraction peaks. 


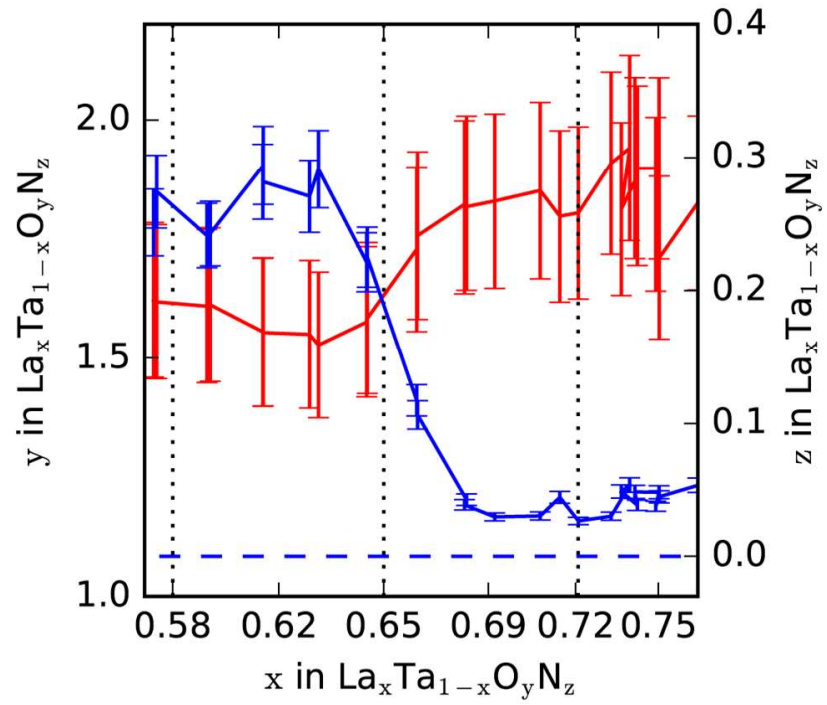

Figure 3. WDS-determined oxygen (y subscript, red line) and nitrogen (z subscript, blue line) concentration as a function of La cation fraction ( $\mathrm{x}$ ) in the $\mathrm{La}_{\mathrm{x}} \mathrm{Ta}_{1-\mathrm{x}} \mathrm{O}_{\mathrm{y}} \mathrm{N}_{\mathrm{z}}$ library.

Table 1. For the 3 representative samples, the WDS-determined composition and formula unit (F.U.) from the ICDD-matched phase from Figure 2 are shown. The corresponding La:Ta and $\mathrm{O}: \mathrm{N}$ ratios, which are $\mathrm{x}$ and $\mathrm{y} / \mathrm{z}$ in $\mathrm{La}_{\mathrm{x}} \mathrm{Ta}_{1-\mathrm{x}} \mathrm{O}_{\mathrm{y}} \mathrm{N}_{\mathrm{z}}$, respectively are calculated with WDS-based values shown next to F.U.-based values in parantheses.

\begin{tabular}{|c|c|c|c|c|}
\hline Sample & WDS composition & ICDD F.U. & $\mathrm{x}\left(\mathrm{x}_{\mathrm{F} . U .}\right)$ & $\begin{array}{c}\mathrm{y} / \mathrm{z} \\
\left(\mathrm{y} . \mathrm{U} / \mathrm{z}_{\mathrm{F} . U .}\right)\end{array}$ \\
\hline $\mathrm{A}$ & $\mathrm{La}_{0.58} \mathrm{Ta}_{0.42} \mathrm{O}_{1.62} \mathrm{~N}_{0.27}$ & $\mathrm{LaTaON}_{2}$ & $0.58(0.5)$ & $6(0.5)$ \\
\hline $\mathrm{B}$ & $\mathrm{La}_{0.65} \mathrm{Ta}_{0.35} \mathrm{O}_{1.63} \mathrm{~N}_{0.19}$ & $\mathrm{LaTaON}_{2}$ & $0.65(0.5)$ & $8.58(0.5)$ \\
\hline $\mathrm{C}$ & $\mathrm{La}_{0.72} \mathrm{Ta}_{0.28} \mathrm{O}_{1.8} \mathrm{~N}_{0.03}$ & $\mathrm{La}_{3} \mathrm{TaO}_{7}$ & $0.724(0.75)$ & $60(\infty)$ \\
\hline
\end{tabular}




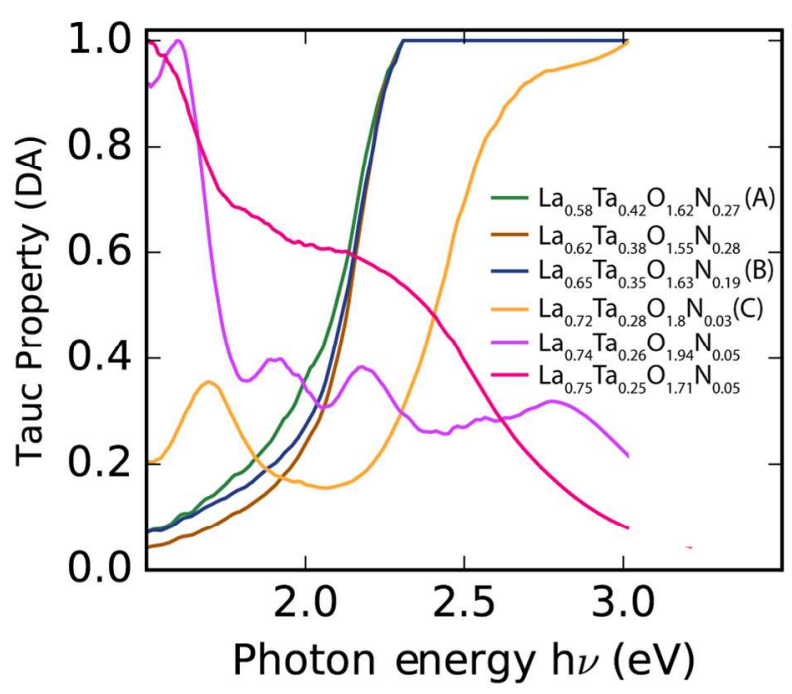

Figure 4. Direct-allowed Tauc plots of representative compositions for $0.58<\mathrm{x}<0.75$ in the $\mathrm{La}_{\mathrm{x}} \mathrm{Ta}_{1-\mathrm{x}} \mathrm{O}_{\mathrm{y}} \mathrm{N}_{\mathrm{z}}$ library. The Tauc plots are scaled by their maximum value and labelled by the thin film composition with the 3 representative samples noted. The green, brown and blue patterns correspond to the $\mathrm{LaTaON}_{2}$ phase and the orange pattern corresponds to the nitrogen-containing $\mathrm{La}_{3} \mathrm{TaO}_{7}$ phase. For $0.58 \leq \mathrm{x} \leq 0.65$, the diffuse reflectance signal was indistinguishable from dark noise at photon energies greater than about $2.3 \mathrm{eV}$ due to the high absorption well above the band agp energy, which is plotted as a saturated Tauc signal.

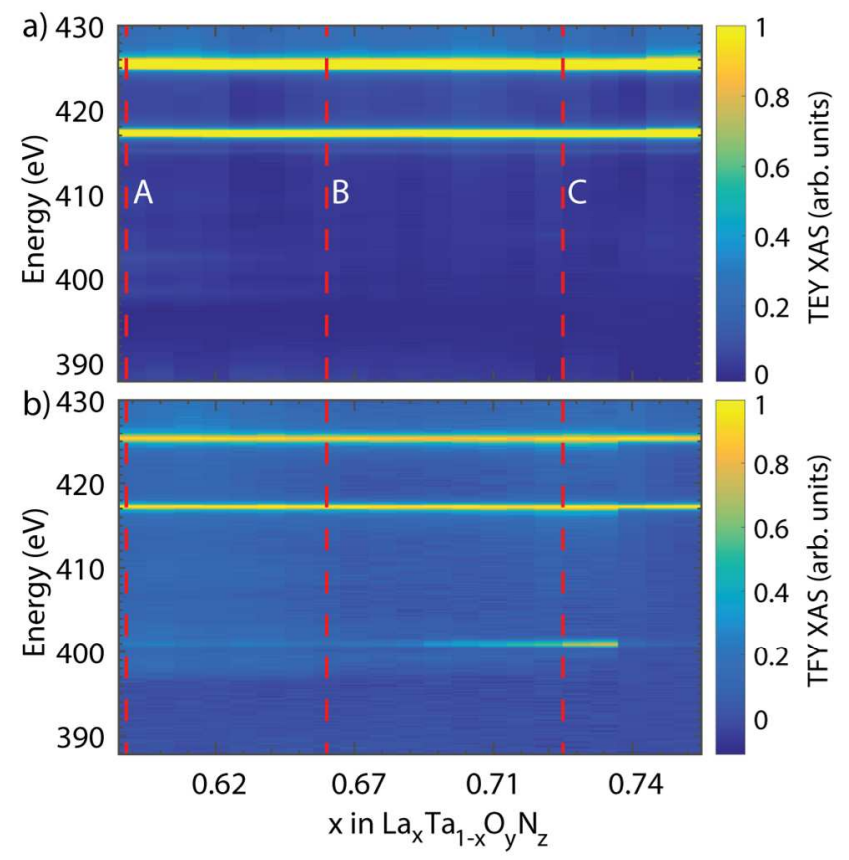

Figure 5. a) TEY and b) TFY of N K-edges as a function of La cation fraction $\mathrm{x}$ in $\mathrm{La}_{\mathrm{x}} \mathrm{Ta}_{1-\mathrm{x}} \mathrm{O}_{\mathrm{y}} \mathrm{N}_{\mathrm{z}}$. 


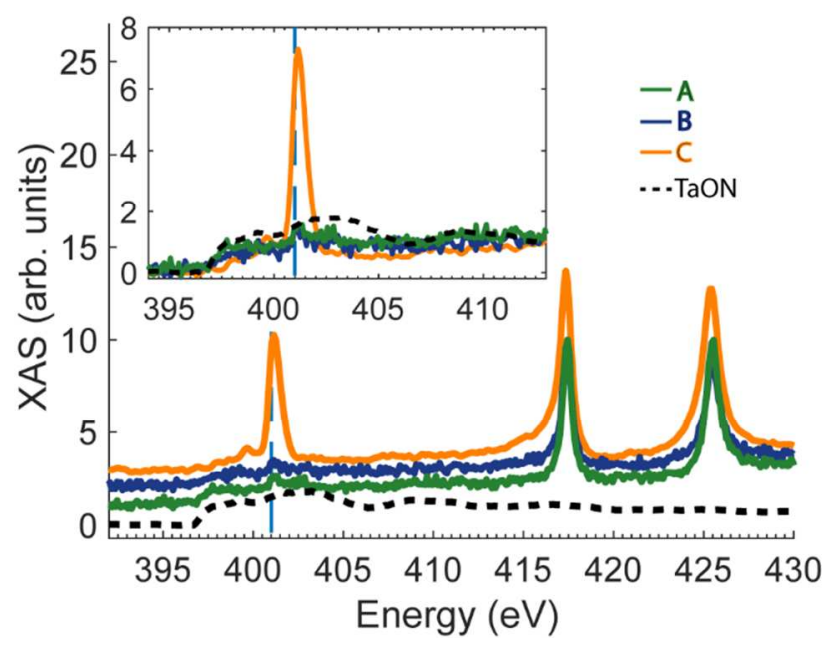

Figure 6. TFY of N K-edges for representative samples A $\left(\mathrm{La}_{0.58} \mathrm{Ta}_{0.42} \mathrm{O}_{1.62} \mathrm{~N}_{0.27}\right)$, B $\left(\mathrm{La}_{0.65} \mathrm{Ta}_{0.35} \mathrm{O}_{1.63} \mathrm{~N}_{0.19}\right), \mathrm{C}\left(\mathrm{La}_{0.72} \mathrm{Ta}_{0.28} \mathrm{O}_{1.8} \mathrm{~N}_{0.03}\right)$, and $\mathrm{TaON}$ reference material. The dashed blue line at $401 \mathrm{eV}$ corresponds to the $1 s \rightarrow \pi^{*}$ transition of $\mathrm{N}_{2}$, which describes the signal from sample $\mathrm{C}$. The full spectra are plotted with vertical offset for clarity and in the region with different $\mathrm{N}-\mathrm{K}$ features is shown in the inset with no offset. 
For Table of Contents Use Only

\section{Combinatorial Discovery of Lanthanum-Tantalum Oxynitride Solar Light Absorbers with Dilute Nitrogen for Solar Fuels Applications}

Santosh K. Suram ${ }^{\mathrm{a}}$, Sean W. Fackler ${ }^{\mathrm{b}}$, Lan Zhou ${ }^{\mathrm{a}}$, Alpha T. N'Diaye ${ }^{\mathrm{c}}$, Walter S. Drisdell $^{\mathrm{b}}$, Junko Yano ${ }^{\mathrm{b}, \mathrm{d} .}$, John M. Gregoire ${ }^{\mathrm{a}, *}$
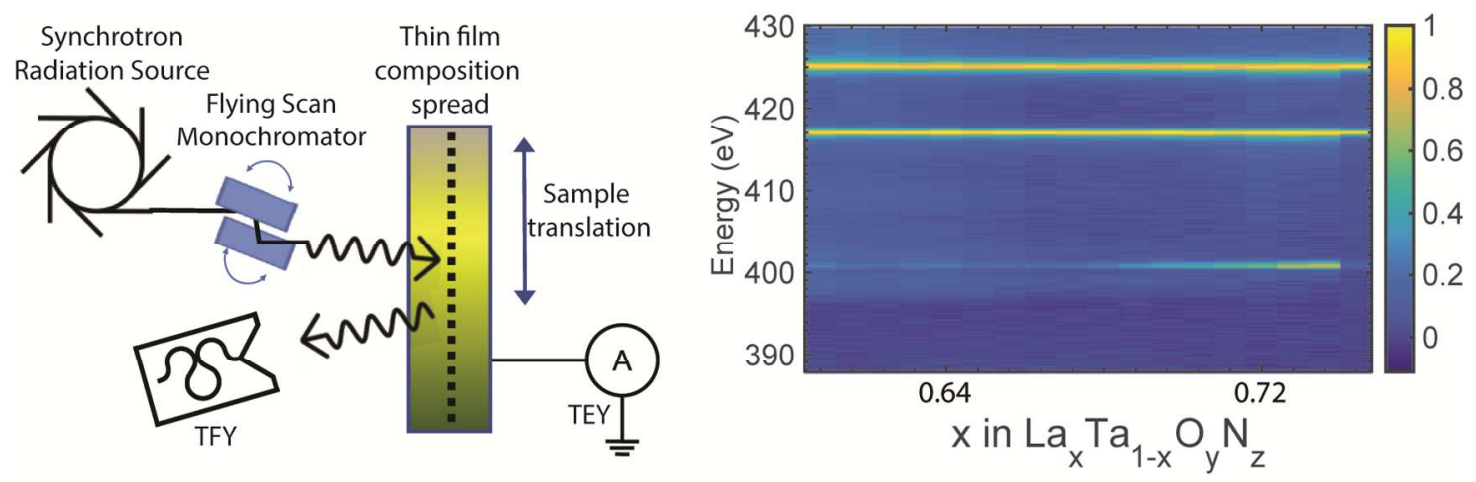